\title{
PERBANDINGAN DAYA TARIK PEMBACA TERHADAP KONTEN INFOGRAFIS BATAM POS VERSI CETAK DAN ONLINE
}

\author{
Dhimas Aditya', Condra Antoni' ${ }^{2}$ \\ 1,2Multimedia \& Jaringan, Jurusan Teknik Informatika, Politeknik Negeri Batam \\ dhimasaditya366@gmail.com
}

\begin{abstract}
Abstrak
Perkembangan teknologi informasi memberikan kontribusi nyata terhadap perkembangan media dalam bentuk maupun sajian informasinya yang sekaligus juga memberikan dampak pada khalayak dalam mengaksesnya. Berdasarkan hasil wawancara penulis dengan beberapa konsumen berita tersebut didapatkan dari 20 orang yang diwawancarai ternyata hanya 5 diantaranya yang mengonsumsi berita melalui media cetak (koran). Dimana ini membuktikan bahwa media cetak mengalami penurunan ketertarikan pembaca. Namun pada akhir-akhir ini banyak media koran yang menggunakan infografis sebagai media visual sebagai penampung dari berita-berita, maka dari itu penulis melakukan perbandingan bagaimana pengaruh infografis yang ada pada media cetak dan media online di Batam Pos akan mempengaruhi ketertarikan pembaca. Pada penelitian ini menggunakan metode kuantitatif komparatif dengan melakukan beberapa analisis pendukung. Hasil dari perhitungan data yang ada menunjukkan bahwa infografis pada media cetak lebih memiliki peran terhadap pengaruh ketertarikan pembaca dibanding media online.
\end{abstract}

Kata Kunci: Batam Pos, infografis, ketertarikan pembaca, media

\begin{abstract}
Technological developments make a real contribution to the development of media in the form of any information presentations that also have an impact on the audience in accessing it. Based on result interviews with several consumers obtained from 20 people interviewed, only five were approved who consumed the news through print media (newspapers). This proves that print media cancel the decline in reader interest. However, in recent years many media newspapers have used graphics as visual media as news collectors. Therefore the writer wants to compare how the influence of installing infographics in printing and online media in Batam Pos will be interested in attracting readers. This study using a comparative quantitative method by conducting several supporting analyzes. The result of the existing data indicates that infographic in printing media has an important role in influencing readers interest compared to online media.
\end{abstract}

Keywords: Batam Pos, media, infographic, reader's interest 


\section{PENDAHULUAN}

Perkembangan era modern ini telah banyak menyumbangkan kontribusi nyata terhadap perkembangan media dalam bentuk maupun sajian informasinya yang sekaligus juga memberikan dampak pada khalayak dalam mengaksesnya. Perkembangan era modern yang pesat itu juga berdampak pada industri media. Salah satu nya media digital yang mendapatkan dampaknya. Bahkan sudah banyak kalangan mulai memprediksi media cetak akan tergusur oleh media berbasis digital. Dalam Buku Phillip Meyer terbitan 2006, Philip Meyer memprediksi pada tahun 2044 nantinya hanya akan ada satu jenis koran. Dimana telah menjadi pertanyaan besar bagi masa depan koran ditengahnya gempuran dengan media elektronik seperti Televisi, radio, internet (Meyer, 2009). Bahkan banyak tinjauan yang membuktikan peran media cetak mulai terkikis media online.

Berdasarkan hal tersebut maka penulis sudah mensurvei apakah hal di atas benar-benar yang sedang dialami, maka penulis melakukan wawancara dengan beberapa konsumen berita dari berbagai kalangan umur 20 - 30 tahun yang telah berlangganan koran Batam Pos, mengenai apakah berita yang mereka dapatkan sehari hari didapatkan melalui media cetak (koran) atau dari media online. Berdasarkan hasil wawancara penulis dengan beberapa konsumen berita tersebut didapatkan dari 20 orang yang diwawancarai ternyata hanya 5 diantaranya yang mengkonsumsi berita melalui media cetak (koran). Dimana ini membuktikan bahwa media cetak mengalami penurunan ketertarikan pembaca khususnya di kalangan umur 20 - 30 tahun. Oleh karena itu, media cetak, khususnya portal berita Batam Pos membutuhkan cara dalam menyajikan data informasinya ke dalam tampilan yang lebih menarik untuk dibaca. Infografis merupakan gabungan kata dari informasi dan juga grafis, dimana infografis adalah suatu media yang berguna untuk mempresentasikan suatu data yang kompleks sehingga dapat mudah dipahami oleh khalayak umum (Carmack, 2015). Dan diharapkan infografis ini dapat sebagai media pemahaman yang bersifat fungsional, estetika dan juga informatif.

Permasalahannya, media komunikasi untuk menyampaikan berita pada media cetak dan media online cenderung hanya menggunakan foto biasa saja, sehingga masyarakat kurang memiliki ketertarikan untuk membaca khususnya di kalangan umur 20 hingga 30 tahun. Hal ini tidak sebanding dengan media-media online yang mudah di akses dan memiliki fitur lebih banyak dalam menarik perhatian pembaca, sehingga bagaimana membuat sebuah media infografis yang dapat menarik pembaca pada media di Batam Pos (cetak dan online) terkhususnya media cetak. dan bagaimana dari hasil data-data penelitian yang nanti nya didapati bisa di analisis perbandingan nya antara media cetak dan online sehingga mendapatkan hasil yang diharapkan

Berangkat dari persoalan tersebut, penulis perlu merumuskan sebuah media komunikasi guna memenuhi hak masyarakat, khususnya media komunikasi yang tepat untuk menyampaikan sebuah informasi kepada pembaca koran Batam Pos. Media menjadi sarana komunikasi efektif dalam penyampaian pesan. Media memiliki kekuatan untuk mempengaruhi khalayak. Media juga memiliki jangkauan yang luas dalam menyebarkan berbagai pesan. Dalam penelitian ini, infografis akan diimplementasikan sebagai media 
yang akan memberikan informasi tentang berita-berita utama, khususnya berita "Liputan khusus" pada koran Batam Pos. Dalam hal ini infografis dimaksudkan untuk mengkomunikasikan informasi secara visual dengan menggunakan berbagai bentuk seperti gambar, warna, tulisan (Qudratina \& Antoni, 2018).

\section{METODE PENELITIAN}

Metode yang digunakan dalam penelitian ini adalah menggunakan metode kuantitatif komparatif dimana metode ini dilakukan untuk mencari perbandingan antara satu variabel dengan variabel yang lainnya, dengan tujuan mencari tahu apakah ada perbedaan atau tidak pada dua variabel yang diuji (Sugiyono, Metode Penelitian Kuantitatif, Kualitatif, dan R\&D, 2017). Tahapan pengumpulan data nya dibagi menjadi dua tahap, yaitu wawancara kepada ahli, serta penyebaran angket. Untuk data angket akan diolah menggunakan software spss. Setelah semua data dikumpulkan maka akan dilakukan perhitungan serta pembahasan, dan tahapan terakhir yakni memberikan kesimpulan dan saran. Penelitian ini dilakukan pada daerah Batam dengan jangkauan umur 20-30 tahun yang berlangganan koran dan objek penelitian ini adalah infografis yang terbit di halaman cetak dan online Harian Pagi Batam Pos.

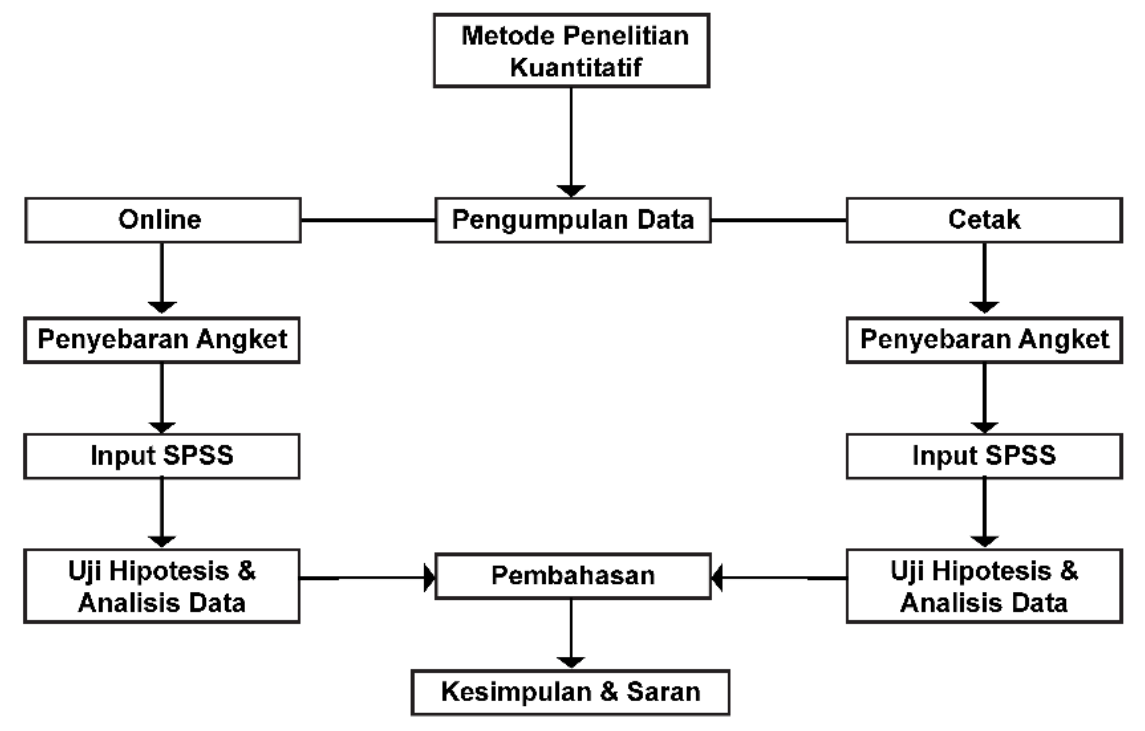

Gambar 1. Prosedur Perancangan

[Sumber: Dokumentasi Penulis]

Teknik analisis data dilakukan dengan 3 tahap yaitu pertama melakukan uji validitas terhadap hasil kuesioner dan bahan yang telah ada kepada 10 ahli pada bidang desain grafis, kemudian tahap selanjut nya melakukan uji reliabilitas terhadap hasil kuesioner dan bahan yang telah ada kepada 30 responden kriteria penulis. Dan tahap terakhir yaitu melakukan uji $\mathrm{t}$ terhadap hasil responden kuesioner serta mencari hasil data apakah sesuai dengan hipotesis di awal.

Segmentasi dan Targeting:

Pembagian Segmentasi pada penelitian ini adalah masyarakat yang berada di kota Batam yang dimana penulis rincikan Kembali menjadi masyarakat yang berada di daerah 
Batam Centre dengan kriteria pekerjaan bebas dan mengutamakan mereka yang sudah pernah berlangganan koran Batam Pos atau media cetak lain nya

Dan pembagian target dari infografis ini adalah pada orang pembaca aktif koran Batam Pos dengan rentang usia 20 hingga 30 tahun, dan juga mereka yang sudah terbiasa dengan layout dan desain dari media cetak sebelum nya. Respon yang diharapkan adalah dapat meningkatkan ketertarikan pembaca terhadap berita yang disajikan melalui media infografis ini dan juga dapat memahami nya dengan baik, sehingga berita yang ingin disampaikan oleh Batam Pos dapat tersampaikan.

\section{HASIL DAN PEMBAHASAN}

Berdasarkan metode penelitian yang telah dijelaskan di bab sebelumnya, maka hasil yang dicapai dalam penelitian ini menghasilkan data-data berupa data kuesioner terhadap ahli dan responden. Berikut hasil pengisian kuesioner yang ditunjukkan pada tabel dibawah ini

Tabel 1 Hasil Pengisian Kuesioner

[Sumber: Dokumentasi Penulis]

\begin{tabular}{|l|l|l|l|l|l|}
\hline \multicolumn{7}{|c|}{ Hasil Kuesioner Media Cetak } \\
\hline & SS & S & KS & TS & STS \\
\hline Total & 63 & 27 & 16 & 1 & 3 \\
\hline Rata-Rata & 9 & 18 & 2 & 1 & 1 \\
\hline \multicolumn{7}{|c|}{ Hasil Kuesioner Media Online } \\
\hline \multicolumn{7}{|c|}{ SS } & S & KS & TS & STS \\
\hline Total & 80 & 118 & 11 & 0 & 1 \\
\hline Rata-Rata & 11 & 16 & 1 & 0 & 1 \\
\hline
\end{tabular}

Dari hasil pengisian kuesioner yang di lakukan pada ahli dan responden sesuai aspek penilaian (warna, layout, konten) maka didapati untuk kedua kuesioner ini mendapatkan hasil yang tinggi dan juga rendah ini dikarenakan penggunaan warna pada media cetak ini cenderung kurang maksimal ini dikarenakan media cetak menggunakan mesin cetak yang kurang optimal serta kertas yang digunakan sudah mengandung warna abu-abu sehingga untuk beberapa orang melihatnya menjadi tidak setuju. Sedangkan pada media online hasil yang didapatkan lebih mengarah kepada kemudahan akses nya yang dapat diakses dari mana saja. Kedua hasil ini hanya berlaku untuk daerah perkotaan dan kemungkinan akan berbeda ketika dilakukan di daerah yang agak terpencil. Dimana ini merupakan perbandingan hasil survei antara media cetak dan media online dari segi kombinasi warna, peletakan judul, ukuran dari icon dan karakter yang dapat dilihat pada grafik yang ada pada gambar dibawah ini 


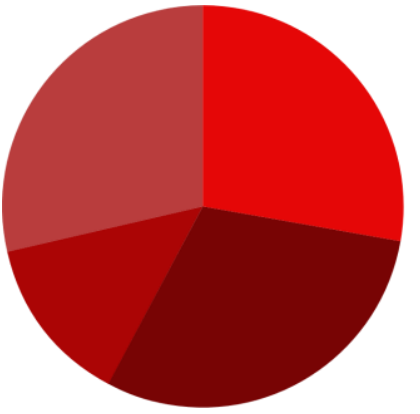

Media Cetak

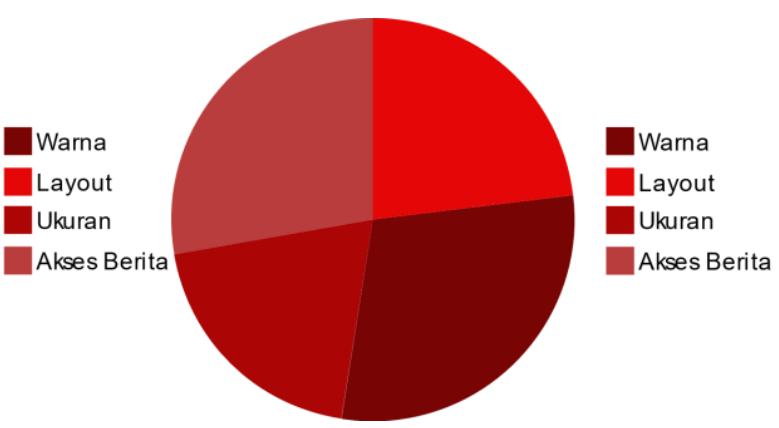

Media Online

Gambar 2. Jawaban responden terhadap kuesioner

[Sumber: Dokumentasi Penulis]

Berdasarkan hasil pengujian dengan ahli desain grafis, didapati bahwa produk infografis yang digunakan sebagai bahan penelitian ini sudah memenuhi standar kelayakan untuk dapat digunakan kepada khalayak umum, dari segi penggunaan warna, perletakan layout, penggunaan icon dan karakter, serta pemilihan font. Semua aspek yang telah disebutkan itu telah memenuhi kelayakan dari apa yang penulis ujikan ke ahli desain grafis. Berikut merupakan contoh produk yang telah diuji kepada ahli desain grafis

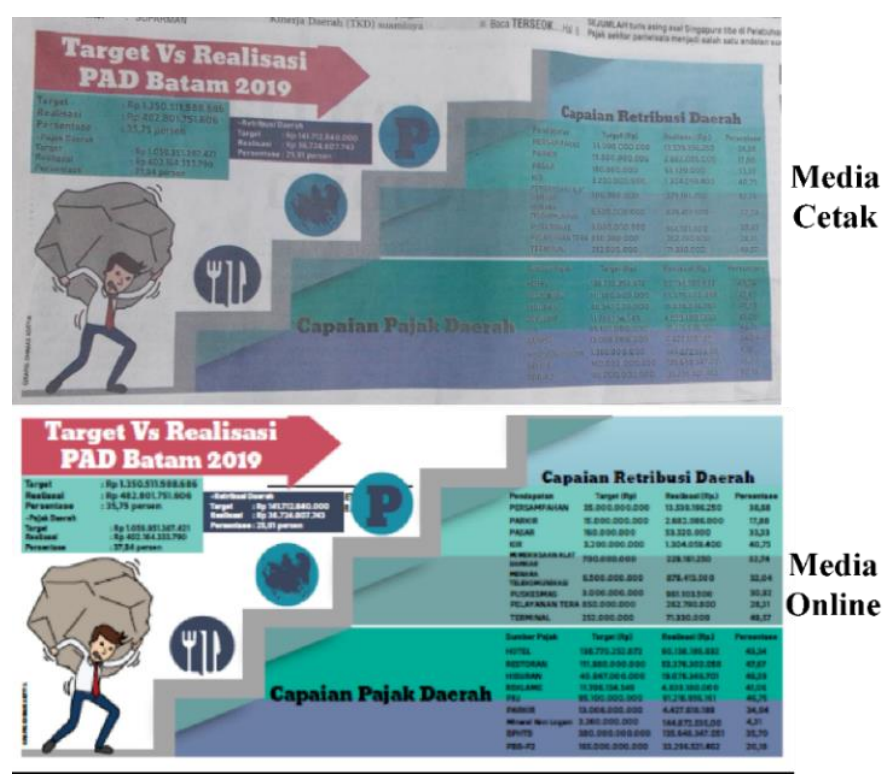

Gambar 2. Tampilan infografis media cetak dan media online [Sumber: Dokumentasi Penulis]

Berdasarkan hasil data yang sudah didapatkan, maka penulis melanjutkan menguji data menggunakan uji validitas. Dan dari hasil yang diperoleh dari pengujian validitas, seluruh item pernyataan yang digunakan terbukti sudah valid dan dapat digunakan pada responden sesuai kriteria, sesuai tabel dibawah ini. 
Tabel 2. Hasil Uji Validitas Media Cetak

[Sumber: Hasil Pengolahan Data Primer, 2020]

\begin{tabular}{|c|l|l|l|l|}
\hline No & \multicolumn{1}{|c|}{ Indikator } & \multicolumn{1}{|c|}{$r$ hitung } & \multicolumn{1}{|c|}{$r$ tabel } & Keterangan \\
\hline 1 & Aspek Desain: & & & \\
& $\bullet$ Indikator 1 & 0,772 & 0,632 & Valid \\
& - Indikator 2 & 0,813 & 0,632 & Valid \\
& $\bullet$ Indikator 3 & 0,910 & 0,632 & Valid \\
& -Indikator 4 & 0,840 & 0,632 & Valid \\
& $\bullet$ Indikator 5 & 0,840 & 0,632 & Valid \\
\hline 2 & Implementasi Media: & & & \\
& $\bullet$ Indikator 6 & 0,772 & 0,632 & Valid \\
& - Indikator 7 & 0,772 & 0,632 & Valid \\
& $\bullet$ Indikator 8 & 0,910 & 0,632 & Valid \\
\hline 3 & Pemahaman Konten: & & & \\
& $\bullet$ Indikator 9 & 0,840 & 0,632 & Valid \\
& $\bullet$ Indikator 10 & 0,772 & 0,632 & Valid \\
& $\bullet$ Indikator 11 & 0,660 & 0,632 & Valid \\
\hline
\end{tabular}

Tabel 3. Hasil Uji Validitas Media Online

Sumber: Hasil Pengolahan Data Primer, 2020

\begin{tabular}{|c|c|c|c|c|}
\hline No & Indikator & r hitung & $r$ tabel & Keterangan \\
\hline 1 & $\begin{array}{l}\text { Aspek Desain: } \\
\text { - Indikator } 1 \\
\text { - Indikator } 2 \\
\text { - Indikator } 3 \\
\text { - Indikator } 4 \\
\text { - Indikator } 5\end{array}$ & $\begin{array}{l}0,948 \\
0,728 \\
0,920 \\
0,850 \\
0,850\end{array}$ & $\begin{array}{l}0,632 \\
0,632 \\
0,632 \\
0,632 \\
0,632\end{array}$ & $\begin{array}{l}\text { Valid } \\
\text { Valid } \\
\text { Valid } \\
\text { Valid } \\
\text { Valid }\end{array}$ \\
\hline 2 & $\begin{array}{l}\text { Implementasi Media: } \\
\text { - Indikator } 6 \\
\text { - Indikator } 7 \\
\text { - Indikator } 8\end{array}$ & $\begin{array}{l}0,681 \\
0,681 \\
0,850\end{array}$ & $\begin{array}{l}0,632 \\
0,632 \\
0,632\end{array}$ & $\begin{array}{l}\text { Valid } \\
\text { Valid } \\
\text { Valid }\end{array}$ \\
\hline 3 & $\begin{array}{l}\text { Pemahaman Konten: } \\
\text { - Indikator } 9 \\
\text { - Indikator } 10 \\
\text { - Indikator } 11\end{array}$ & $\begin{array}{l}0,948 \\
0,681 \\
0,948\end{array}$ & $\begin{array}{l}0,632 \\
0,632 \\
0,632\end{array}$ & $\begin{array}{l}\text { Valid } \\
\text { Valid } \\
\text { Valid }\end{array}$ \\
\hline
\end{tabular}

Selanjutnya penulis melakukan uji reliabilitas untuk mengetahui koefisiennya dengan menggunakan metode Alpha Cronbach, dengan nilai $\alpha$ (koefisien reliabilitas) harus minimal 0,60. Dan hasil pengujian nya terbukti bahwa seluruh aspeknya "Reliabel" seperti tabel dibawah ini. 
Tabel 4. Hasil Uji Reliabilitas

[Sumber: Hasil Pengolahan Data Primer, 2020]

\begin{tabular}{|l|c|c|l|}
\hline \multicolumn{1}{|c|}{ Variabel } & Cronbach's Alpha $(\alpha)$ & N & \multicolumn{1}{|c|}{ Status } \\
\hline $\begin{array}{l}\text { Penerapan Infografis } \\
\text { pada Media Cetak }\end{array}$ & 0,653 & 30 & Reliabel \\
\hline $\begin{array}{l}\text { Penerapan Infografis } \\
\text { pada Media Online }\end{array}$ & 0,806 & 30 & Reliabel \\
\hline
\end{tabular}

Setelah itu dilakukan Uji t untuk menilai perbedaan antara nilai tertentu dengan ratarata kelompok populasi. Dan melihat apakah hasil yg didapatkan sesuai dengan Ho dan Ha yang telah ditetapkan seperti dibawah ini.

Ho : Berarti infografis pada media cetak lebih memiliki peran terhadap pengaruh ketertarikan pembaca dibanding media online.

$\mathrm{Ha}$ : Berarti infografis pada media online lebih memiliki peran terhadap pengaruh ketertarikan pembaca dibanding media cetak.

Dengan kriteria pengujian terhadap hipotesis yang ditentukan adalah sebagai berikut:

Ho diterima dan Ha ditolak jika t hitung $\leq \mathrm{t}$ tabel

Ho ditolak dan Ha diterima jika t hitung $>$ t tabel

Tabel 5. Hasil Uji t

[Sumber: Hasil Pengolahan Data Primer, 2020]

\begin{tabular}{|l|c|c|c|c|}
\hline \multicolumn{1}{|c|}{ Variabel } & t hitung & t tabel & N & Status \\
\hline $\begin{array}{l}\text { Media Cetak dan } \\
\text { Media Online }\end{array}$ & 0,715 & 2,750 & 30 & Ho diterima \\
\hline
\end{tabular}

Maka hasil analisis uji t terhadap penerapan infografis pada Media Cetak dan Media online diperoleh 0,715 $<2,750$, dengan tingkat signifikansi 0,000 (dibawah 0,05). Maka hal ini mengidentifikasikan bahwa hipotesis Ho diterima, sehingga dapat diambil kesimpulan bahwa penerapan infografis pada media cetak lebih memiliki peran terhadap pengaruh ketertarikan pembaca pada koran Batam Pos.

\section{KESIMPULAN}

Berdasarkan hasil pengisian kuesioner yang dilakukan oleh responden dapat dilihat bahwa infografis yang diterapkan di media cetak dan media online pada Batam Pos memiliki peran yang baik dalam menarik ketertarikan pembaca, dibuktikan dengan hasil pengisian di kedua jenis kuesioner (media cetak dan online) dimana mendapatkan respon setuju. Dan berdasarkan ini, peneliti sudah bisa membuat sebuah infografis yang dapat menarik ketertarikan pembaca baik pada media cetak maupun media online.

Berdasarkan hasil pengujian hipotesis (uji t) hasil analisis yang diperoleh bahwa infografis di media cetak lebih mempengaruhi ketertarikan pembaca dibandingkan media online. Dibuktikan dengan $t$ hitung $-2,174<t$ tabel 2,750 dengan tingkat signifikansi 0,000 (dibawah 0,05), dimana Ho diterima yaitu Berarti infografis pada 
media cetak lebih memiliki peran terhadap pengaruh ketertarikan pembaca dibanding media online.

Bagi pihak manajemen Batam Pos, dari hasil penelitian ini diketahui bahwa penerapan infografis pada media cetak dan media online berpengaruh positif dalam ketertarikan pembaca, maka dari itu pihak perusahaan hendaknya terus melakukan inovasi, kreatifitas dan observasi terhadap kebutuhan dan selera pembaca guna mendapatkan perhatian, minat baca atau minat beli yang terus meningkat serta mampu mempertahankan hal positif dimata para pembaca, mengingat semakin banyak pesaing nyata yang bermunculan pada saat ini serta persaingan di dunia digital yang semakin ketat.

\section{DAFTAR PUSTAKA}

Carmack, J. (2015). Data visualisation vs Infographic. Data 101 visage.

Meyer, P. (2009). The Vanishing Newspaper: Saving Journalism In the Information Age. Missouri: University Missouri Press.

Qudratina, Q., \& Antoni, C. (2018). Visualisasi Pesan Gizi Seimbang Menggunakan Aspek Spatial, Temporal, Live Action, Dan Typography. (Vol. 1). JOURNAL OF DIGITAL EDUCATION, COMMUNICATION, AND ARTS (DECA).

Riyantini, R., \& Triarosdianan, S. (n.d.). Efektivitas Infografis Media Online (Survey Pemberitaan Tempo.co Pada Mahasiswa Perguruan Tinggi Swasta Kopertis Wilayah III).

Sugiyono. (2009). Metode Penelitian Bisnis. Bandung: CV Alfabeta.

Sugiyono. (2017). Metode Penelitian Kuantitatif, Kualitatif, dan R\&D. Bandung: CV Alfabeta.

Taufik, M. (2012). Infografis Sebagai Bahasa Visual Pada Surat Kabar. 11, 157. 